\title{
Global Supply Chains Development on the Basis of Russia and Kazakhstan Economies Digitalization
}

\author{
Sergey Barykin \\ dept. of International economic relation \\ Saint Petersburg State Marine Technical \\ University \\ St. Petersburg, Russian Federation \\ ORCID: 0000-0002-9048-009X
}

\author{
Elena Smirnova \\ dept. of Logistics and SCM \\ Saint Petersburg State University of \\ Economics \\ St. Petersburg, Russian Federation \\ smirnova-ea@list.ru
}

\author{
Petr Sharapaev \\ dept. of Logistics and SCM \\ Saint Petersburg State University of \\ Economics \\ St. Petersburg, Russian Federation \\ radugapetr@mail.ru
}

\begin{abstract}
The market economy of Eastern Europe and Asia is gradually approaching the level and quality characteristics of the OECD countries. Global economy's transition to a qualitatively new stage of globalization after the global crisis of $\mathbf{2 0 0 8}$ 2009, is characterized by a number of changed qualitative and quantitative features showing that the rates of world trade are outpacing domestic production. According to the estimates until 2030, service industries will move into a phase of intensive development; and due to the advanced development of new types of services, the share of developing countries in the global market of services will rise. The logistics platform implementation in the practice of managing Russian-Kazakhstan supply chains is a promising tool for increasing the level of logistical integration between countries and optimizing the logistics activities of all participants in supply chains.
\end{abstract}

Keywords-digital economy, logistics, innovation, international supply chain management

\section{INTRODUCTION}

Taking these prospects into account, the integration potential of Russia in the conditions of gradual trade and economic unity of the ASEAN countries can be considered in the aspect of formation of new strategic opportunities for interaction with the integration environment of Eurasia on the basis of investments in infrastructure development within the framework of the Eurasian Economic Union (EEU). Rapid qualitative breakthrough of the Russian economy is closely connected with the concept of creating a reliable logistics hub in international trade between actively developing economies of Russia and Kazakhstan on the basis of international cooperation within the framework of the actively developing EEU (in 2018, the temporary agreement on FTZ with Iran was signed, the agreement on trade and economic cooperation with China was signed and the Republic of Moldova was granted an observer country status). Various integration associations have become a natural result of further development and internationalization of production. The Eurasian Economic Union (EEU) has become a new model of regional integration in Eurasia. The EEU is a strategically important tool for the Russian Federation, used to create innovatively active logistics systems. According to the definition by Professor V.V. Shcherbakov, we will consider a set of elements forming the entirety for the management of material flows, starting with the supply of raw materials and up to the delivery to the final consumer [1] as a logistical system. Recent published works of Russian scientists [2-6] reveal the innovative context of the main transformations of modern economy, involving a scientific search for the fundamental approaches of theoretical research in digitalization of logistics, and assessment of their practical results. Digitalization is currently a fundamental trend of modern economy's development. The basis of the trend is digital technologies actively used by enterprises.

\section{MATERIALS AND METHODS}

Information technologies development provides synthesis of models of management of material and financial flows in the process of management of supply chains [7].

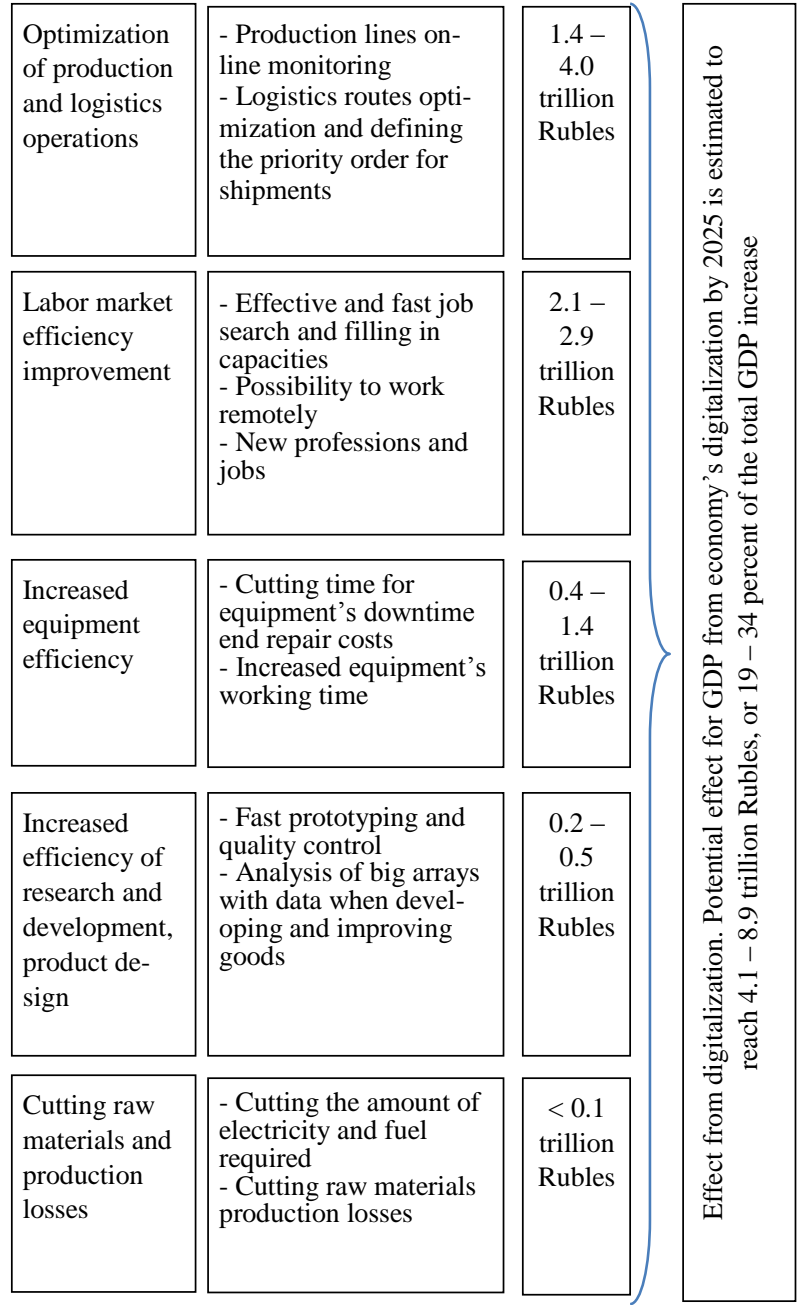

Fig. 1. Sources of GDP growth by 2025 due to digitalization, trillion Rubles, according to 2015 prices [8]

According to McKinsey consulting company, one of the main sources of GDP growth in Russia is implementation of the potential, that is identification of the correct priority of shipments and the correct logistics optimization (Fig. 1); the role of digitalization in the Russian economy's growth is 
estimated at 19 to 34 percent of real GDP growth from 2015 to 2025. One can agree with Professor T.G. Shulzhenko about the fundamental importance of identifying the signs that distinguish the logistical system on a global scale from the one on a national scale to be able to identify the global logistical system [9, pp. 537 - 538]. M.A. Parfenov analyzed the types of supply chains taking into account the complexity of approaches to supply chains management; and based on the analysis he determined the types of global supply chains using empirical and morphological approach [10]. The conceptual framework should be supplemented by the category of digital platforms superseding classical agents [11]. Right now the scientists identify three stages of economy's digitalization development process presented as a set of three platforms (Fig. 2).

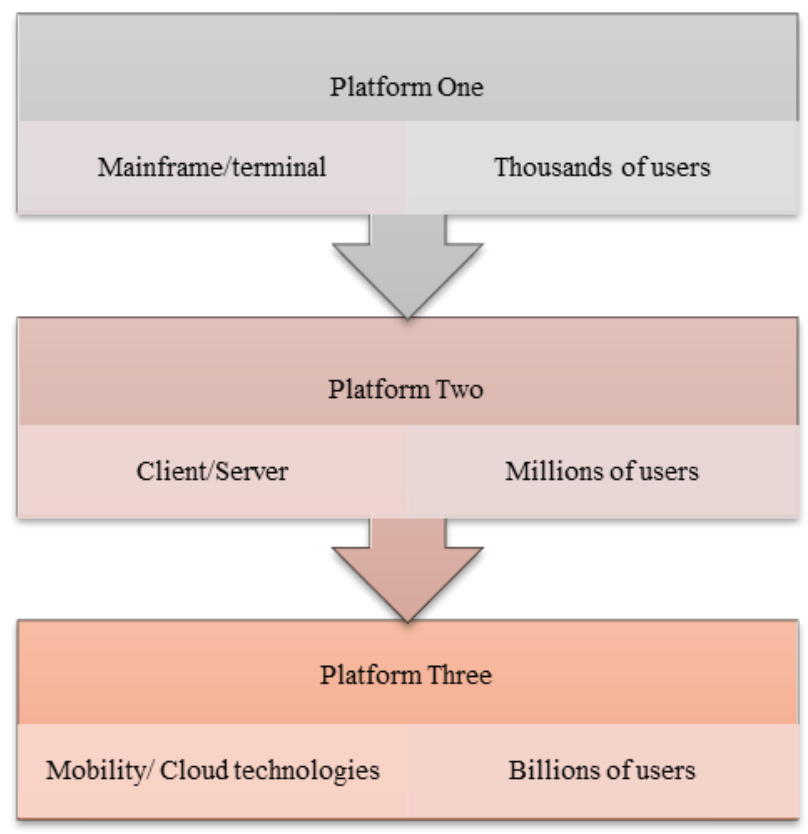

Fig. 2. Digitalization Development Platforms

The basis of the first level in our case is numerous mainframes, as well as terminals, used by many users as a platform for various applications.

The backbone of Platform Two is PCs, they work based on the Internet and use the client-server architecture. At this level, we can see a significant increase in both the number of users and the applications used.

The third level of digitalization's development is characterized by a developed cloud structure used to solve a complex of analytical tasks, as well as by a large number of devices connected permanently to the network. At this level we can already see billions of users who use content, as well as various services created on the basis of this level.

One should take into account that a large amount of data, calculations, mobile, social and other technologies of this level all push the system itself to self-development by stimulating mutual development of all its elements: the manyfold increasing interested users produce more and more information to be stored using cloud technologies.

The growing activity in social networks is affected by the increase in the number of user mobile devices. At this level
Big Data-technologies should be used: they will help analyze the behavior of gadgets owners based on content analysis.

So, here we have defined the foundation on which the Platform Three rests: cloud services, mobile technologies, Big Data and social technologies. Let's now analyze each element in detail. Thus, Big Data technology shall be treated as new technologies with variability, allowing to operate different format data from different sources, as well as to extract information by fast (real-time) capturing and multi-step analysis of heterogeneous data. The amount of data in this case is huge. Tens of terabytes. It means that Big Data features are a huge amount of processed data, speed and variability. The global spending movement on Big Data goes up (Fig. 3).

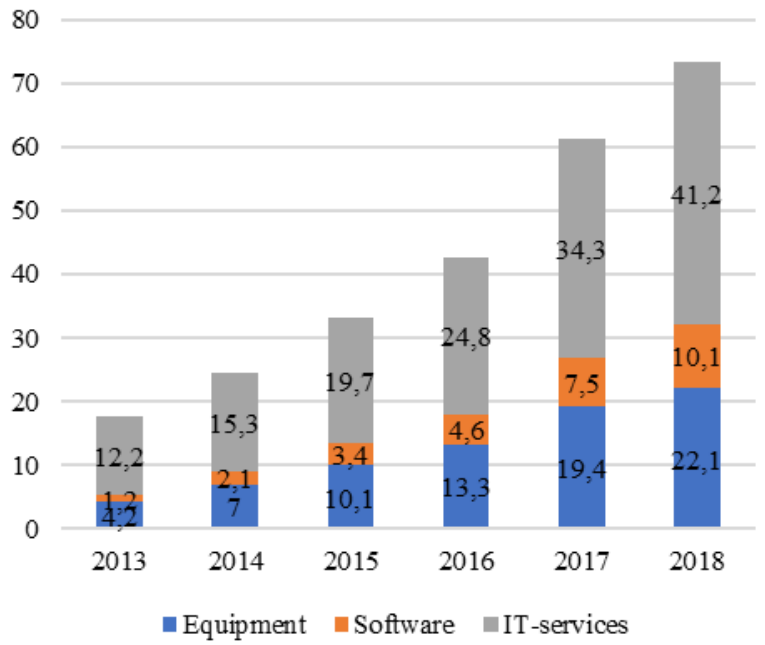

Fig. 3. Global Big Data spending, billion dollars [12]

The modern stage of logistics development is characterized by the key importance of technological solutions that provide remote access via mobile devices to a variety of information resources, stored mainly in the cloud. At the same time, cloud services contribute to saving, both through virtualization principles, shared use of information resources, and through shared use of applications and standardization of the necessary equipment. Global spending on cloud technologies is constantly growing (Fig. 4).

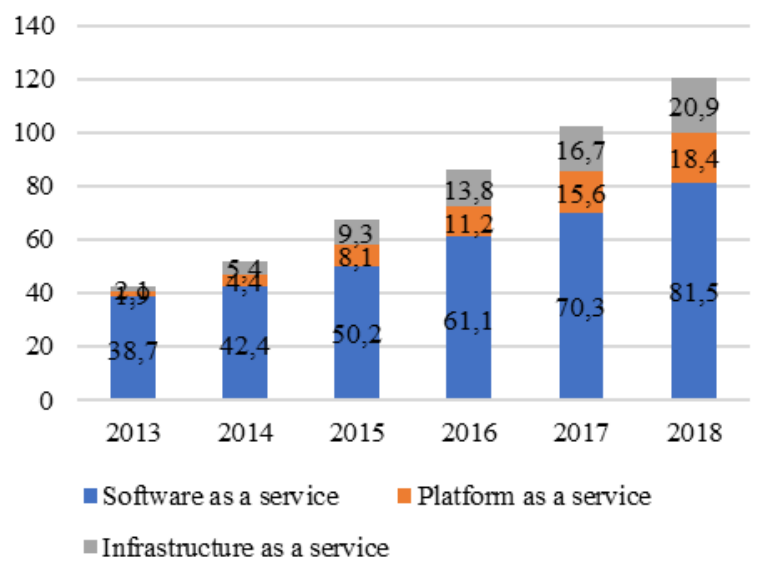

Fig. 4. Global spending on cloud technologies, billion dollars [10] 
Analyzing the Figure, IT technology costs grew five times slower in 2013-2018 compared to cloud technologies spending, which indicates the growing popularity of the latter. So, currently $1 / 7$ part of the largest software developers receive most of their revenue in cloud technologies. In 2017, the costs on cloud storage and processing of data array models exceeded $\$ 100$ billion [13]. Therefore, Platform Three implies both technological innovations and innovations in the sector of consumption, stimulating the emergence of new business models.

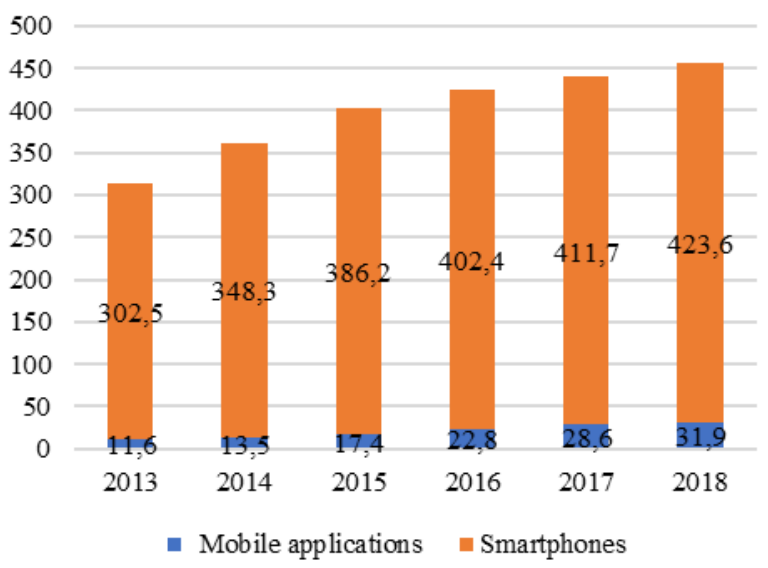

Fig. 5. Global Spending on Mobile Technologies [13]

The key role of Platform Three is strongly influenced by the widespread of mobile devices. The rate of growth in sales of this kind of equipment is pushing companies to develop technological solutions (for example, specialized mobile applications) providing safe interaction of personal mobile devices with corporate IT environment. As a result, today most applications have a mobile version.

It stands to reason that the widespread use of mobile applications by individuals leads to market growth as well. Figure 5 shows global spending on mobile technologies. In modern conditions, we can observe the following interesting trend: social networks are becoming increasingly popular as a tool for promoting goods and attracting customers.

So, “... in 201880 percent of Fortune 500 companies had active online communities of their consumers." [14]. It is a social network that becomes an integral component of marketing strategy, through which the company can analyze the opinion of users on product improvement, identification of shortcomings, which play a key role in the development of planning solutions for future developments.

\section{RESULTS}

Thus, it is possible to distinguish a number of factors that ensure the accelerated development of logistics technologies on the basis of Platform Three:

1. Self-service through the transition of costs to purchase IT solutions and IT infrastructure development in logistics to the level of lease payments, combined with a significant acceleration of implementation of these decisions. As shown earlier in the document, technological solutions of the previous Second Platform identify high capital costs (acquisition of IT solutions) and long installation time. Based on the Third Platform we can see the following.

2. Third Platform sales channels that promote enterprise applications through the cloud technologies and enterprise resources on which their mobile versions are located, differ from sales channels based on the Second Platform for distribution of enterprise applications through different levels of partners, which requires higher resource costs than marketing based on the Third Platform.

3. Availability of information resources through cloud technologies allows people to gain access to information/solutions anywhere in the world, anytime, from a desktop or a mobile device.

4. The cost of logistics services based on the Third Platform implies the development of various pricing models that allow costs reduction by focusing on actual consumption (customer orientation).

We assume that the development of logistics technologies based on the technologies of the Third Platform will increase the key role of innovations in the field of information storage and processing together with the complex of analytical methods of making logistics decisions.

Within the framework of the digital economy, a new organizational structure of business is being developed - the blockchain system. The strong point of the system is its decentralization, allowing to carry out instant and transparent transactions all over the world. Therefore, for the business to function it is not necessary to open several offices and employ people to work there.

Block chain allows to form a low-cost business structure, including a small number of internal specialists. In addition, many employees can stay all around the world. For example, the IMG global agency employs only 60 employees and a small number of advertising managers. One employee is responsible for Russia, and this is enough [15]. Global decentralization accelerates intercountry borders erosion, and as the blockchain expands, many multinational companies are predicted to emerge.

Digital technologies lead to saving and sometimes to no transaction costs whatsoever. This creates new opportunities for the business, but it also creates new demands to it by the market and consumers. As a result, product and company life cycle is going down. Thus, S\&P 500 rating showed the life cycle of large corporations going down from 60 years to 18 [16].

In the conditions of digitalization, strategies of interaction with customers and customers servicing technologies change fundamentally. As a result, marketing channels, both distribution and communication one transform respectively.

More and more companies become aware of the need to use digital technology in supply chains. However, in general one can tell that in modern conditions the level of logistics digitalization remains quite low due to the fact that the majority of logistics enterprises continues to use outdated communications, for example, phone and email communications, and regard the path importer — dealer retail network to promote goods as the main one. It is necessary to understand that modern conditions of business development stimulate us to master methods of direct access 
to the consumer (preferably automated)), operate huge amounts of information, and be able to exchange it, building a blockchain, as well as making decisions for the future.

The Digital Supply Chain Institute (DSCI) conducted its own survey of supply chain professionals and found that one third of this group is either extremely or moderately unfamiliar with the blockchain. Only one percent of organizations taking part in the survey, currently use blockchain in their supply chain operations, and 35 percent are only studying the possibilities of it.

The American Productivity and Quality Center (APQC) conducted a survey, interviewing 101 logistics specialists. As a result, it was revealed that about $1 / 3$ of the interviewers understand the blockchain technology's potential to create a competitive advantage of the company over the next 10 years. About 10 percent of respondents believe that blockchain will change the industry over the stated period.

Leading global logistics companies closely monitor all modern trends in IT and look for opportunities to implement them in their business. For example, IBM / Maersk cooperation. These companies announced the creation of a corporation to develop a trading blockchain platform for the logistics industry.

The vast majority of large logistics companies are now at a stage of accumulation of information, and world analysts note that it is possible to apply it in the implementation of technologies in artificial intelligence. Data analysis can not only optimize the activity of logistics providers, but give a serious advantage. Thus, DHL released an interesting indicator that gives an idea of the current state and possible trends in the development of world trade.

Today, the EEU is the most successful integration structure operating in the post-Soviet space. Within the framework of the EEU such structures as the Customs Union of Belarus, Kazakhstan and Russia, the Anti-Crisis Fund and the Center for High Technologies of the EEU were created. One should take into account such advantage of the EEU as a powerful transit and transport potential of the member states of the community. Effective implementation of existing transit and transport potential in the context of community functioning involves achieving a high level of logistics integration between member states of the community.

To date, the integration processes taking place within the framework of the EEU are carried out in the conditions of digitalization of the economy of the member states of the community. In accordance with the program "Digital Kazakhstan" approved in 2016 at the state level by the Republic of Kazakhstan [17] for 2017-2020, the development of the following sectors is expected:

1) Digital Silk Road, which includes guidelines for the development of high-tech digital infrastructure (through the provision of broadband Internet access in rural areas, development of telecommunications hub, information security, construction of data centers (data processing centers);

2) creative society, formed on the basis of human capital development and trained based on digital literacy of the population, qualification of specialists in the sector of information and communication technology and creative thinking;

3) digital transformation in the sectors of economy, including on the basis of automation of transport and logistics system of the country, infrastructure development to ensure the activity of "smart" cities;

4) a proactive state, the meaning of which is to develop electronic and mobile government (digital government), as well as the development of a network of public services in electronic form, national spatial data infrastructure.

It should also be noted that the development of RussianKazakh logistics networks on the basis of digitalization is of great importance for the actively developing economies of Russia and Kazakhstan and regional integration in the Eurasian space, as the geographical position of Kazakhstan is the defining item in the Europe-Asia transport service.

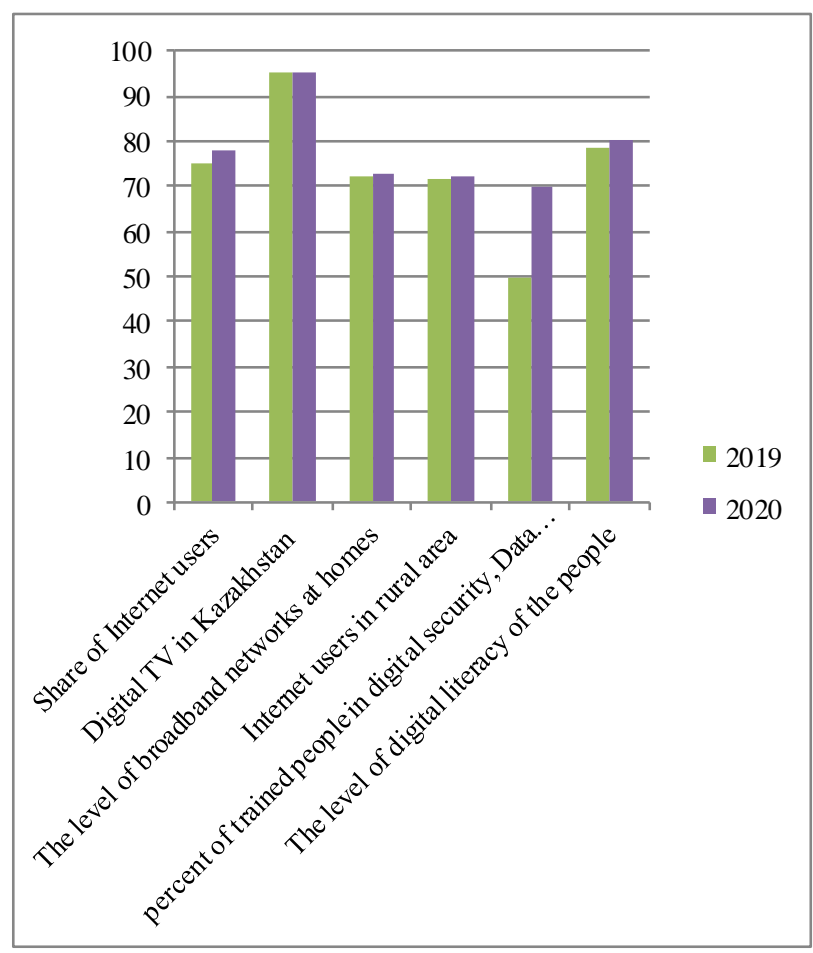

Fig. 6. The use of digital technologies by the population of the country [16]

A number of prerequisites for Kazakhstan's formation of transport and logistics hub can be identified.

1. Customs Union and Common Economic Area: unified tariffs, a single customs territory at the border with EU countries and China.

2. Investments of Kazakhstan in infrastructure: construction of the highway "West China - West Europe", development of airport infrastructure, construction of a network of terminals and transport and logistics centers on the territory of the Republic of Kazakhstan.

3. Improvement of logistics services, simplification of border crossing procedures: application of the principles of $5 \mathrm{~S}$ (speed, service, sum, safety, stability); automation of transport control processes of the Ministry of Transport of the Republic of Kazakhstan; electronic provision of public services. 
4. Work on improving the efficiency of logistics systems of Kazakhstan according to the LPI index of the World Bank.

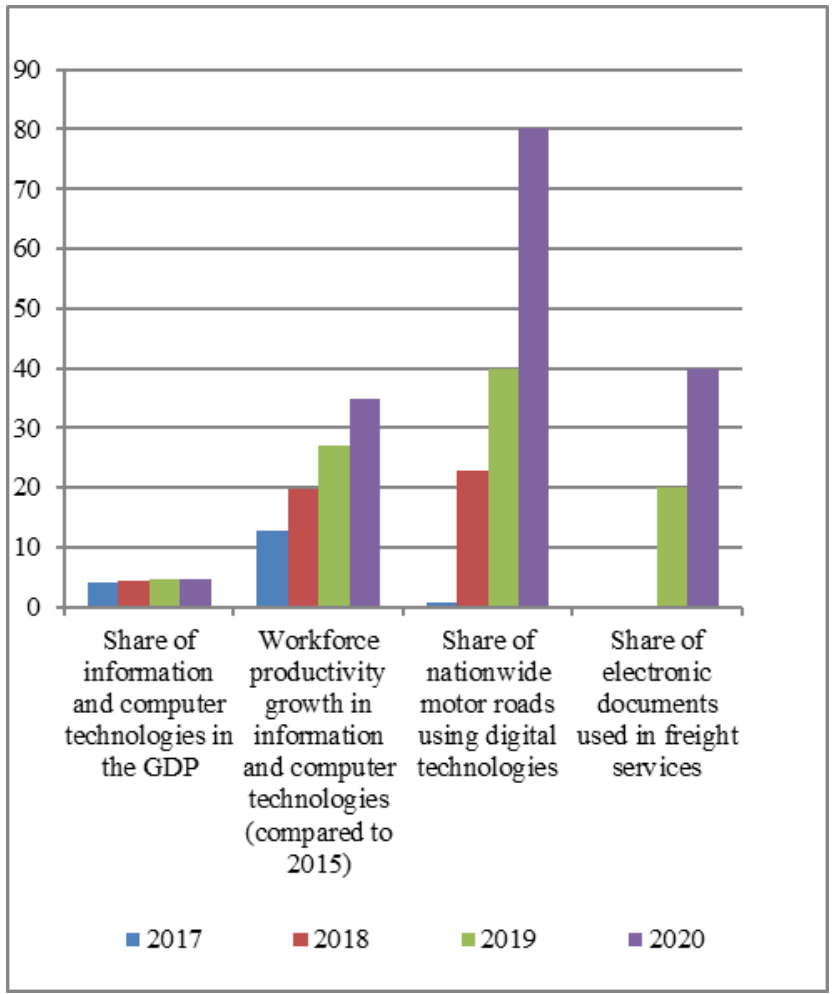

Fig. 7. The use of digital technologies in transport and logistics $[16,17]$

Here we will provide the trend of digitalization in the Republic of Kazakhstan (partially: the use of digital technologies by the population of the country (Fig. 6), the use of digital technologies in transport and logistics (Fig. 7) in accordance with the digital potential up to 2020 inclusive, approved at the State Program "Digital Kazakhstan". This process addresses the challenge of creating a reliable, accessible and secure information and communication infrastructure.

\section{DISCUSSION}

In the context of digital transformation of the economy, the development of the digital industry, digital technologies in agriculture and industry, it is obvious that the Customs Union's operation is aimed at the development of intercountry trade between the members of the Union and therefore a priori implies simplification of customs procedures, reduction of administrative and legal barriers in intercountry trade. Accordingly, logistics integration of supply chains by the members of the Customs Union is an important aspect of development of intercountry trade on the way to achieve a new level of EEU functioning in the global community.

According to S.S. Sidorsky, the Minister of Industry and Agroindustrial Complex of the EEC, the EEU states need to streamline the work on implementation of national digital programs. This will give an opportunity to develop system projects, as well as to develop common digital technological solutions. Examples of joint projects in the sector of digital economy include the Eurasian Industrial Cooperation Network and the Eurasian Technology Transfer Network.

There is a need to create a scientific and practical concept of logistics systems aimed at integration of Russian and
Kazakh supply chains in order to optimize logistics activities of partners in both countries.

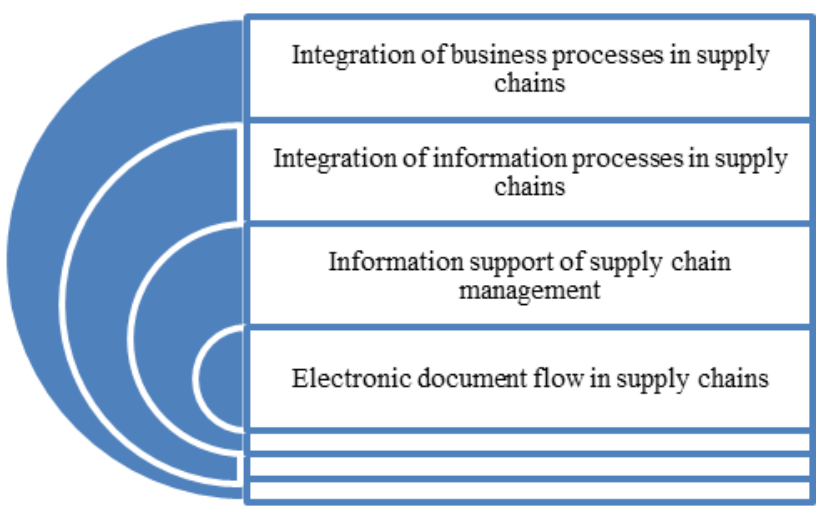

Fig. 8. Logistics Platform Function

A logistics platform implementation is offered as a way to improve integration of supply chains of Russia and Kazakhstan in the conditions of digitalization of the economy. The logistics platform is an information and communication system, the functions of which are shown in Figure 8.

The logistics platform can solve the following challenges in the area of international supply chain:

- the buyer selects its supplier in shorter terms;

- the buyer uses resources more efficiently;

- the time required for calculation of time and cost of delivery goes down;

- efficiency of business processes streamlining and improving through electronic document management;

- improved efficiency of control of logistics business processes.

The logistics platform allows to ensure full transparency of logistics processes for all participants: the results of each logistics process become known in real time to all participants.

\section{CONCLUSION}

Thus, the following advantages of using the logistics platform as an instrument of integration of supply chains of Russia and Kazakhstan in the conditions of digitalization of the economy can be identified:

- increased level of logistics service due to reducing delivery time and increasing customer satisfaction;

- improved coordination of inventory management with other business processes of supply chain participants;

- reduced logistics costs associated with stocks management;

- reduced labor costs for logistics operations;

- reduced duration of logistics operations;

- reduced logistics risks in the supply chain.

Therefore, the logistics platform implementation in the practice of management of Russian-Kazakh supply chains is a 
promising tool to increase the level of logistics integration between the countries and optimizing the logistics activities of all participants in the supply chain.

\section{REFERENCES}

1. Logistics and Supply Chain Management: Textbook for bachelor's degree students / ed. by V.V. Shcherbakova. - M. : Yurayt Publishing House, 2019. 582 p

2. Silkina G.Yu. Innovative Processes in Digital Economy. Information and Communication Drivers. / G.Yu. Silkina, S.Yu. Shevchenko. St. Petersburg.: Polytechnic University Publishing House, 2017 - 262 p.

3. Silkina G.Yu. Modern Trends of Logistics Digitalization / G.Yu Silkina, V.V. Shcherbakov. - St. Petersburg.: POLYTEKH-PRESS, 2019. $237 \mathrm{p}$.

4. Kuleshova, E., Levina, A., Esedulaev, R. Reengineering of supply chain management integrated scheduling processes (2018) 193, № 05064 .

5. Ilin, I., Kalinina, O., Barykin, S. Financial logistics innovations in IT Project Management (2018) 193, статья № 05062.

6. Shcherbakov V.V. Basics of Logistics: Textbook for universities V.V. Shcherbakov // SPb. : Peter. - p. 2009. - p. 51.

7. Shcherbakov V.V. Logistics System of Corporate Finance Management / V.V. Shcherbakov, S.E. Barykin. - St. Petersburg: Publishing House of the Saint Petersburg University of Economics, 2018, 195 p.

8. Digital Russia: A New Reality. July 2017. [Electronic resource]. Access Mode: https://www.mckinsey.com/ru/our-insights (date of access: June 16, 2019)

9. Shulzhenko T.G. Evolution of the Concept of Global Logistics in the Context of Modern Conditions of Internationalization of Globa Economy. Logistic Systems in the Global Economy. 2016. No. 6. pp. 391-395.

10. Parfenov M.A. Types of Supply Chains and Features of Their Streaming Processes // "Vestnik of the Astrakhan State Technical University". Series - Economics. 2010. - No. 2. - p. 167-169.

11. EEU TRANSCOR. Development of Transport Corridors and Transport Infrastructure. Digital Economy Development Fund "Digital Platforms". 2018

12. IT: Global Market [Electronic resource]. - Mode of access: http://www.tadviser.ru/index.php/Article: ИТ_(мировой_рынок) (date of access: April 21, 2019)

13. Review and Assessment of Development Trends of the World and Russian Markets of Information Technologies [Electronic resource]. Access mode: https://habr.com/company/moex/blog/250463/ (date of access: April 22, 2019)

14. Industry 4.0 Open Access Miracles - OPENACCESS. [Electronic resource] - Access mode: http://www.absmagazine.ru/article/promyshlennost-40-chudesa-otkrytogo-dostupaopenaccess (date of access: May 11, 2019)

15. Safronchuk M. V. Digital Steps of the Revolution (Fourth Industrial Revolution and Digital Transformation) // Economics and Management: Problems, Solutions. - 2017. — No. 11. VOL. 5. - P. $52-56$

16. Foresight Technologies of Marketing: Monograph / G.A. Bagiev, A.A Dligach, Yu.N.Solovyova; under scientific editorship of G.L. - SPb. Asterion, 2016. — p. 71

17. Analysis of World Experience of Industry Development and Approaches to Digital Transformation of Industry of the Member States of the Eurasian Economic Union: Research and Information Technologies [Electronic resource]. - Access mode: http://www.eurasiancommission.org (date of access: April 22, 2019)

18. JSC "National Information and Communication Holding "Zerde" https://www.zerde.gov.kz/

19. Website of the Competitiveness Council of Kazakhstan: http://competitivenes.kz/competitiveness/31/

20. Building a Digital Culture, Best practice guide, 2017. [Electronic resource]. - Access Mode: https://www.econsultancy.com/re ports/building-a-digital-culture/ (date of access: April 18, 2019)
21. Gartner Identifies Five Emerging Technology Trends That Will Blur the Lines Between Human and Machine [Electronic resource]. Access Mode: https://www.gartner.com/en/newsroom/pressreleases/2018-08-20-gartner-identifies-five-emerging-technologytrends-that-will-blur-the-lines-between-human-and-machine (date of access: May 15, 2019) 